\title{
Predator-prey overlap induced Holling type III functional response in the North Sea fish assemblage
}

\author{
Alexander Kempi ${ }^{1,2, *}$, Jens Floeter ${ }^{1,3}$, Axel Temming ${ }^{1}$ \\ ${ }^{1}$ Zentrum für Meeres- und Klimaforschung, Institut für Hydrobiologie und Fischereiwissenschaft, Olbersweg 24, \\ 22767 Hamburg, Germany \\ ${ }^{2}$ Present address: Johann Heinrich v. Thünen Institut, Institut für Seefischerei, Palmaille 9, 22767 Hamburg, Germany \\ ${ }^{3}$ Present address: Johann Heinrich v. Thünen Institut, Institut für Fischereitechnik und Fischereiökonomie, Palmaille 9, \\ 22767 Hamburg, Germany
}

\begin{abstract}
Understanding the response of predator populations to varying prey fields is a prerequisite for understanding prey population dynamics and to correctly parameterise multi-species stock assessment or ecosystem models. Previous analyses on the large scale feeding response of predator populations, however, came to unrealistic results for the North Sea. The observed feeding response types (e.g. negative prey switching) would lead to the extinction of prey populations when these become scarce. We analysed the large scale response of North Sea cod Gadus morhua and whiting Merlangius merlangus populations to varying prey fields using Generalised Additive Models (GAMs). Thereby, we took changes in predator-prey overlap explicitly into account, in contrast to previous analyses. The composition of the prey field and changes in predator-prey overlap had significant effects on the diet composition in the final GAM, explaining $65.6 \%$ of the variance. The existence of a large scale prey refuge at low prey abundances as proposed by the Holling type III functional response could be demonstrated from field data. The refuge was caused by active prey-switching behaviour of the predators, and also by a passive change in the availability of prey due to changes in predator-prey overlap associated with changes in the prey abundance. In addition, a rapid increase in relative stomach contents was observed if the prey populations passed the abundance threshold of the prey refuge leading to a predator pit. At even higher abundances a saturation effect in relative stomach contents was detected. This study demonstrates that current diet selection models can be significantly improved by taking into account changes in spatial predator-prey overlap.
\end{abstract}

KEY WORDS: Functional response · Holling type III · Predator-prey overlap · Prey refuge • Predator pit

Resale or republication not permitted without written consent of the publisher

\section{INTRODUCTION}

Understanding the mechanisms of fluctuations in fish populations is one of the major tasks in fisheries science. Besides bottom-up processes, which determine especially the food availability for fish larvae, top-down impacts via predation are also key drivers of fish population dynamics inside marine ecosystems (Sissenwine 1984, Mueter et al. 2006). Bax (1991) showed, for 6 different exploited ecosystems, that predation was the main source of mortality for fish beyond larval and early juvenile stages. Predation by fish appeared to be 2 to 35 times higher than the losses to commercial fisheries.
Predation on fish eggs, fish larvae and juveniles also has the potential to determine the survival rate of incoming year classes to a large extent (e.g. Koester \& Moellmann 2000, Kempf et al. 2006).

Therefore, understanding the role of species interactions in regulating populations and community structures is essential to explain past population trajectories and to project potential recoveries of depleted fish stocks (Tsou \& Collie 2001). The question whether predator-prey interactions play a stabilizing or destabilizing role for the dynamics of a prey population has received much attention (Magnusson 1995, Wu \& Loucks 1995). To answer this question the response of predator 
populations towards varying prey fields must be understood. One focus thereby is on the functional feeding response of predators (e.g. Holling 1959, Murdoch \& Oaten 1975). Especially at low prey abundances, different shapes of the functional feeding response lead to significantly different results (Holling 1959). Typical parameterisations of the single resource Holling type III functional feeding response (Holling 1959) show a sigmoidal shape. The same is true for the various multi resource extensions of this functional feeding response type (e.g. Chesson 1983). The sigmoidal shape leads to decreasing predation mortalities when the prey population becomes scarce and prevent prey populations from dying out (Magnusson 1995). This is also called the Holling type III effect. The decrease in predation mortalities at low prey abundances can generally be achieved in 3 ways, either independently or in combination. One explanation is an increase in a predator's preference in line with an increase in prey abundances due to the development of search images (Murdoch 1969). This leads to a switch in the diet composition of a predator towards more abundant prey and a disproportionately higher change in intake rates compared to the changes in prey densities; therefore, this behaviour is called positive prey switching (Murdoch 1969). Such an effect, however, can not only be achieved by an active change in the behaviour of the predator (active switching), but also through a change in the availability of prey resources. For example, changes in spatial predator-prey overlap in conjunction with changes in prey density can lead to a disproportionately high change in proportions of this prey in the diet (passive prey switching, Gentleman et al. 2003). The third possibility is the change in total consumption rates with decreasing abundances of dominant prey populations. Especially in food webs with only a few dominant species (e.g. Baltic and Barent Seas) consumption rates and condition of fish predators were observed to decrease when dominant prey populations collapsed (e.g. Baranova 1992, Marshall et al. 2004).

Most laboratory experiments and field observations, however, revealed a Holling type II functional feeding response (no prey switching; Murdoch \& Oaten 1975) or even negative prey switching as an alternative parameterisation of Holling type III-like functional feeding response types (Larsen \& Gislason 1992, Rindorf et al. 1998). When negative prey switching occurs, a decrease in predator preferences with increasing prey abundances is assumed. Both functional feeding response types with their hyperbolic shapes lead to increasing predation mortalities with decreasing prey abundances and can drive prey populations theoretically into extinction. This is reflected in results of the current North Sea single area multi-species assessment model, the Multi Species Virtual Population Analysis
(MSVPA) (Helgason \& Gislason 1979, Pope 1979). MSVPA predictions led to the extinction of cod when fished with current fishing mortalities (ICES 2003). The MSVPA model is parameterised with a multi-species functional feeding response showing similar properties according to shape and increasing predation mortalities with decreasing prey abundances as a Holling type II functional feeding response. In contrast to Holling's traditional single species feeding response, however, the predators do not respond via changes in consumption rates but via changes in the diet composition (relative stomach contents) in the model. A focus on changes in the diet composition of North Sea fish predators is justified by the observation that total consumption rates were independent from abundance fluctuations of particular prey types in the past (ICES 1991, 1992). It can be assumed that in the North Sea food web, enough alternative prey types are always available to opportunistic predators such as cod Gadus morhua.

Contrary to model predictions, a total extinction of collapsed fish populations was not observed; in other words, the North Sea herring stock recovered from very low abundances (Cushing 1982). Marine food webs also show a high degree of stability in simulations (e.g. Dunne et al. 2005). Trials to implement alternative functional feeding responses, however, showed that only negative prey switching can increase the fit to the sampled North Sea wide stomach data used to parameterise the MSVPA model (Larsen \& Gislason 1992). Negative prey switching would drive prey populations even faster into extinction.

This mismatch between sampled stomach data, field observations and model parameterisations, however, may be caused by scaling problems. It is disregarded that the population functional response probably has to be measured on a longer time scale than the individual one and may be significantly different. In large scale models such as MSVPA the spatial heterogeneity is also not taken into account. Changes in predator-prey overlap are ignored and therefore the variability in available prey fields is potentially underestimated. In other words, a decrease in predator-prey overlap with decreasing prey abundances could lead to passive prey switching. To overcome these model limitations, a more realistic diet selection process submodel needs to be developed and implemented in multi species models. As a prerequisite, the processes determining diet composition of North Sea fish predator populations need to be understood at the spatiotemporal scales relevant to the model.

In this study, we investigated the processes determining the large scale diet composition of North Sea cod and whiting Merlangius merlangus populations. Generalised Additive Models (GAMs) (Hasti \& Tibshirani 1990) were constructed to explain the variability 
in 1st and 3rd quarter mean relative stomach contents of the years 1981, 1985, 1986, 1987 and 1991. In doing so, the impact of interannually varying predator-prey overlap on the diet composition of predator populations as well as the existence of a Holling type III effect at the population level was explored. In a second analysis we investigated processes determining interannual changes in predator-prey overlap. For this purpose density dependent (predator and prey abundance indices) as well as climate related (North Atlantic Oscillation Index; NAO) predictor variables were utilized in GAMs.

\section{MATERIALS AND METHODS}

General ideas and hypotheses. We assume that the large scale diet composition of North Sea fish predator populations in the 1st and 3rd quarter is a function of the species and size composition of the prey field and the spatiotemporal availability of the prey organisms to the predators. It is hypothesized that the relative share in the diet of North Sea fish predators drops for a prey when this prey becomes rare in the field and the spatial predator-prey overlap is additionally reduced. As a further hypothesis we assume that spatial predatorprey overlap is especially low when prey populations become scarce due to a reduction of their area of distribution. Both hypotheses combined lead to reduced predation mortalities at low prey abundances and prevent prey populations from dying out. The hypotheses were tested with GAMs explaining the diet composition or the spatial predator-prey overlap respectively.

Input data for the GAMs. Stomach data: Observed relative stomach contents (weight-based) were available from 5 years $(1981,1985,1986,1987$ and 1991) of North Sea wide stomach sampling exercises (Anonymous 1988, Daan 1989, Hislop et al. 1997) coordinated by the International Council for the Exploration of the Sea (ICES). In these years large numbers of cod and whiting stomachs (Table 1) were sampled to get information on predator diets representative for the entire North Sea area (ICES roundfish areas 1-7).

Five different prey species (cod, whiting, haddock Melanogrammus aeglefinus, Norway pout Trisopterus

Table 1. Stomachs sampled per species and year

\begin{tabular}{|c|c|c|c|c|c|}
\hline \multirow{2}{*}{ Predator } & \multirow[b]{2}{*}{1981} & \multicolumn{3}{|c|}{ - Stomach year } & \multirow[b]{2}{*}{1991} \\
\hline & & 1985 & 1986 & 1987 & \\
\hline $\begin{array}{l}\text { Cod } \\
\text { Gadus morhua }\end{array}$ & 11.333 & 5.265 & 6.697 & 6.297 & 9.706 \\
\hline $\begin{array}{l}\text { Whiting } \\
\text { Merlangius mer }\end{array}$ & $\begin{array}{l}18.908 \\
\text { langus }\end{array}$ & 12.954 & 14.640 & 13.909 & 38.404 \\
\hline
\end{tabular}

esmarkii, and clupeids (Clupea harengus and Sprattus sprattus combined) with 3 length classes each were included in the analysis $(5-<10,10-<15$, and 15$<20 \mathrm{~cm}$ ). Other prey species (e.g. sandeel and crustaceans) were not taken into account due to uncertain information on field abundances in each sampling area.

The mean relative stomach contents for the whole predator population inside the sampling area in a certain quarter and year were derived in 3 calculation steps. First, an arithmetic mean for the weights of a prey trophospecies (certain prey species in a certain length class, $s$ ) found in the stomachs of a predator trophospecies (certain predator species in a certain length class, $p$ ) at time $t$ (year-quarter combination) was calculated for each ICES rectangle $(30 \times 30 \mathrm{n}$ miles) from the disaggregated stomach data on haul level. Incomplete classified prey items (e.g. prey length or species could not be identified) were deleted from the database (14\% of the observations). Secondly, a weighted mean of the weight of a prey trophospecies in the stomachs of a predator trophospecies for the entire sampling area was derived with the square root of the predator's catch per unit effort (CPUE) in each ICES rectangle as a weighting factor. This ensured that stomach samples from areas with high predator abundances were weighted more strongly, which is essential in order to obtain an unbiased estimate of mean stomach contents for the whole predator population. Finally, relative stomach contents $(p)$ were calculated by dividing the weighted mean weight of a prey trophospecies $(\mathrm{wm})$ in the stomachs by the total weighted mean weight of all analysed prey found in the stomachs of a certain predator trophospecies:

$$
p_{[p, s, t]}=\frac{W m_{[s, t]}}{\sum_{s} \sum_{i} W m_{[s, t]}}
$$

The length classes for predators in this study were restricted to cod between $30-50 \mathrm{~cm}$ (length classes 30$<40$ and $40-<50 \mathrm{~cm}$ ) and whiting between $25-40 \mathrm{~cm}$ (length classes $24-<30$ and $30-<40 \mathrm{~cm}$ ) as smaller predators had only small amounts of fish prey in their stomachs and larger predators had too low numbers of observations. The classification of the predator length classes was a direct consequence of the sampling regime in which pooled stomachs were sampled inside an allocated length class (Anonymous 1988, Daan 1989, Hislop et al. 1997).

Abundance estimates: Values for predator and prey abundances in the 1st quarter were derived from the International Young Fish Survey (IYFS, 1981-1990) and the International Bottom Trawl Survey (IBTS, 1991-2005). The English Groundfish Survey (EGFS, 1981-1990) and IBTS (1991-2005) delivered data for the third quarter. An abundance index for each preda- 
tor and prey trophospecies in each ICES rectangle was calculated using the arithmetic mean of all hauls conducted in a certain quarter and year in this rectangle. Subsequently, the mean values of each ICES rectangle were summed to obtain an abundance index for each predator and prey trophospecies in the entire sampling area. While spatial predator-prey overlap was assumed to be a function of the absolute predator and prey abundances, the relative prey abundance inside the prey field was chosen as a predictive variable to explain the diet composition. The relative abundance of each prey trophospecies in the prey field was calculated by dividing the abundance index of each prey by the sum of all prey abundance indices relevant for a predator trophospecies in a certain quarter and year.

Spatial predator-prey overlap: The Schoener Overlap index for resource similarity (Ov) (Schoener 1970) was chosen as an index of spatial predator-prey overlap (Eq. 2). Space is treated as a resource and each ICES rectangle $(m)$ as a resource state. The higher the spatial overlap index value, the larger the availability of the prey to the predator. In the overlap index, ' $p s^{\prime}$ and ' $p p$ ' represent the proportions of the prey $(s)$ and predator $(p)$ trophospecies populations in each ICES rectangle at time $t$ (year-quarter combination). As a measure for predator and prey abundance in an ICES rectangle, the survey catches averaged over all hauls conducted in a certain quarter and year were utilized. The absolute differences between $p s$ and $p p$ were summed over all rectangles (number of ICES rectangles, $n$ ). The overlap index was standardized between 0 and 1 . At a value of 1 , predator and prey populations were distributed identically:

$$
O v_{[p, s, t]}=1-0.5 \sum_{m=1}^{n}\left|p s_{[s, t, m]}-p p_{[p, t, m]}\right|
$$

Climate influence: The potential of climate influence to determine spatial predator-prey overlap was tested by including a climate related proxy variable, the monthly NAO index values for the area between $20^{\circ} \mathrm{N}$ and $90^{\circ} \mathrm{N}$. The data were downloaded from National Oceanic and Atmospheric Administration (NOAA) (www.cpc.noaa.gov/products/precip/CWlink/pna/ nao_index.html). The values were calculated by the Rotated Principal Component Analysis (RPCA) used by Barnston \& Livezey (1987). The final NAO index values utilized in the GAMs consisted of the mean value over the 3 month period belonging to the respective quarters.

Problems associated with data: A major problem was that the spatiotemporal coverage of stomach samples and survey data was often not the same. Therefore, it was decided to draw subsamples from the input data. Only those ICES rectangles were included in a certain year and quarter where stomach data and survey data were available in parallel. Finally, between 27 and 114 ICES rectangles could be selected (Table 2).

GAM structure. We constructed GAMs (Hasti \& Tibshirani 1990) using the S-plus ${ }^{\circledR}$ programming environment. The GAMs for explaining the diet composition as well as the GAMs explaining changes in predator-prey overlap over time had a general form in common:

$$
Y_{p, s, t}=C_{p, s}+\sum_{i} f_{i}\left(X_{i, t}\right)+\text { Error }
$$

The predator $(p)$ and prey $(s)$ trophospecies specific response variable at time $t$ (year-quarter combination) was a function of $X_{i, t}$, the $i$ th predictor variable at time $t$. As smooth function $\left(f_{\mathrm{i}}\right)$ we chose the LOESS smoother to be able to identify non-linear relationships between the predictor variables and the response variables. In addition, a time-independent predator-prey interaction specific correction factor $(C)$ was included in the GAMs. Depending on the response variable, $C$ had different meanings (see below). During the analyses, each predictive variable was tested to have a significant $(\mathrm{p}<0.05)$ non-linear or linear relationship with a step wise simplification of the GAMs. The significance was tested by using an approximate F-test (Hasti \& Tibshirani 1990) to detect a significant increase in explained model deviance. In addition, a pseudo $\mathrm{R}^{2}$ value ([null deviance-residual deviance]/ null deviance) was calculated.

In all GAMs we utilized a quasi likelihood estimation to define the mean-variance relationship of the error. We assumed log as link function and an increasing variance with the mean. This took into account that in all GAMs, proportional data in the range between $>0$ and $<0.6$ were modeled as response variable and that the residuals tended to increase with the mean.

Diet composition: To explain the diet composition of North Sea cod and whiting populations, we started our analyses with the simplest possible GAM. In this GAM the time-independent constant $C$ was included only as

\begin{tabular}{|c|c|c|c|c|c|c|c|c|c|c|}
\hline \multirow{2}{*}{ Predator } & \multicolumn{2}{|c|}{1981} & \multicolumn{2}{|c|}{1985} & \multicolumn{2}{|c|}{1986} & \multicolumn{2}{|c|}{1987} & \multicolumn{2}{|c|}{1991} \\
\hline & Q1 & Q3 & Q1 & Q3 & Q1 & Q3 & Q1 & Q3 & Q1 & Q3 \\
\hline Cod Gadus morhua & 76 & 27 & 114 & 42 & 98 & 40 & 88 & 52 & 113 & 78 \\
\hline Whiting Merlangius merlangus & 53 & 32 & 91 & 52 & 73 & 58 & 82 & 45 & 103 & 110 \\
\hline
\end{tabular}

Table 2. Number of ICES squares included in the analysis per year, quarter (Q) and predator species 
an explaining variable. The value of $C$ was equivalent to the predator-prey interaction specific mean relative stomach content calculated over the years of stomach data. It was assumed that a predator has a fixed prey preference and its diet composition does not vary with changes in the prey field. The GAM was used as a reference model since the simplest assumptions on the diet selection of predators were made. In the next step, we tested whether information on changes in relative prey abundance and predator-prey overlap could explain additional parts of the interannual variability in relative stomach contents. In these more complex models, $C$ served as correction factor to balance differing predator preferences for the different prey trophospecies but also to correct for differences in the catchability of the different prey types. Even if predator preferences were identical for all prey, the sampled relative stomach content at a certain number caught is expected to be higher for prey having low catchabilities than for prey having high catchabilities under the assumption of increasing relative stomach contents with increasing prey abundances. Therefore, $C$ was essential since it was the aim to find general relationships explaining the variability of relative stomach contents between the years for all analysed trophic interactions simultaneously.

Spatial predator-prey overlap: Since the number of possible predator and prey combinations for calculating spatial predator-prey overlap values is huge, we selected 2 interactions to demonstrate the mechanisms affecting spatial predator-prey overlap over time. We chose the interaction between cod as predator and cod as well as clupeids as prey. Cod as prey was selected since for this species a strong decrease in abundance occurred in the last 3 decades (ICES 2005). The relationship between overlap and decreasing prey abundance was especially interesting for this study. Clupeids were chosen as contrast. The abundance of clupeids in the North Sea showed an increasing trend in the last 3 decades (ICES 2004). GAMs were fitted for 2 predator length classes $(30-34.9 \mathrm{~cm}, 35-40 \mathrm{~cm})$ and prey between $10 \mathrm{~cm}$ and $<15 \mathrm{~cm}$ representing the most consumed prey length class in the 1st quarter. The time series was restricted to years after 1984 and to 1st quarter data only to avoid a bias due to incomplete survey coverage as far as possible.

Similar as for explaining the diet composition of North Sea fish predators, for each predator-prey combination the year independent constant $C$ only was included into the reference GAM assuming a constant overlap in time. Then the additional predictor variables were added to explain additional parts of the interannual variability. In these more complex GAMs the constant $C$ corrected for differences in the distribution of the different predator length classes.

\section{RESULTS}

\section{Diet selection}

The reference model assuming time independent constant relative stomach contents could explain $55.2 \%$ of the model deviance. There were marked differences between the predator-prey interactions according to mean level of predicted relative stomach contents ranging from close to 0 to $35 \%$ (Fig. 1). The variability of the relative stomach contents between the sampling years was small in absolute terms for interactions having low mean relative stomach contents. The larger the mean relative stomach contents, however, the more variable were the relative stomach contents between the sampling years.

The differences among the predator-prey interactions according to the mean level and variability of the relative stomach contents were also visible in the constant factor $(C$ ) included in the final model (Fig. 2). The variability between the stomach sampling years was

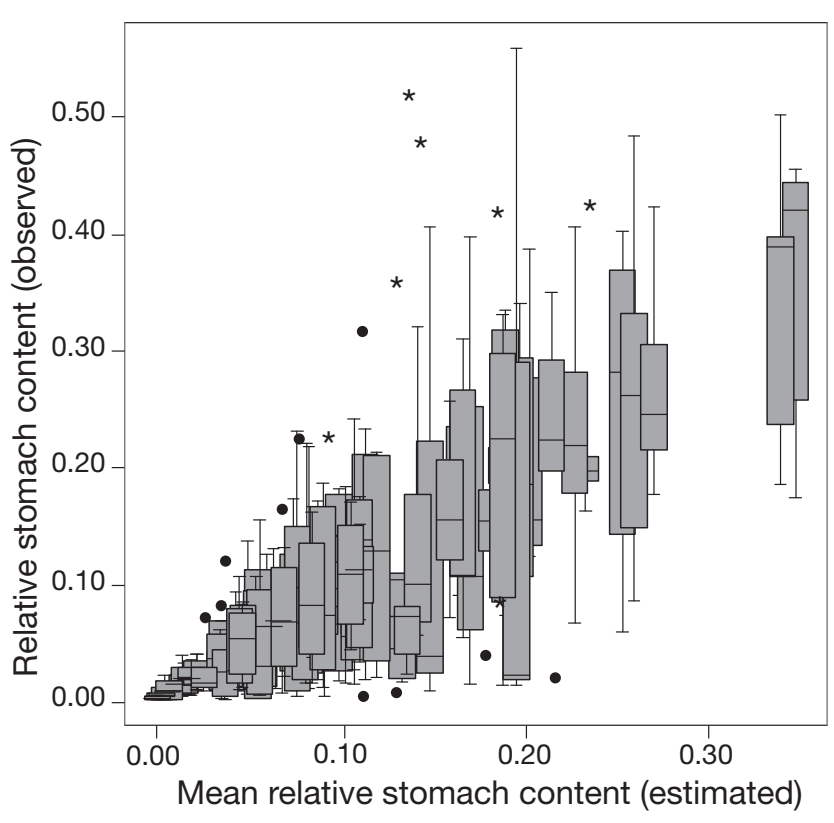

Fig. 1. Overview of relative stomach contents observed in relation to the mean relative stomach content estimated for a particular predator-prey interaction in the reference model. Each box represents the distribution of the observed relative stomach contents over the 5 yr for 1 of the 100 interactions taken into account in the model. The boxes show the median, 25th and 75th percentiles. Whiskers show the range of observed relative stomach contents that are less than 1.5 times the interquartile distance (height of the boxes) away from the upper or lower margin of the boxes. $(\bullet)$ : outliers (1.5 to 3 times the interquartile distance away from the upper or lower margin of the boxes); $\left({ }^{*}\right)$ : extreme values (more than 3 times the interquartile distance away from the upper or lower margin of the boxes 

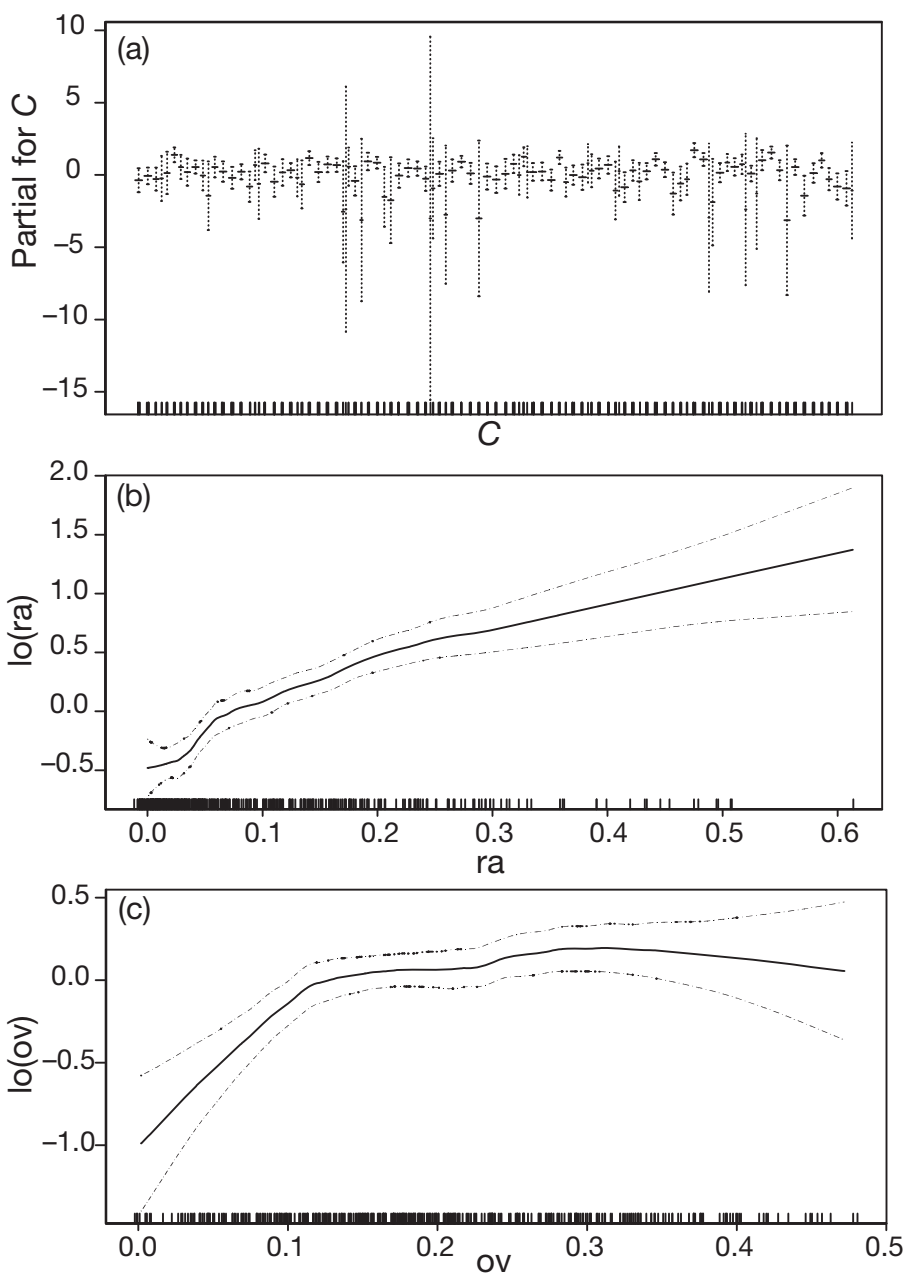

Fig. 2. Fitted relative stomach contents as a function of the relative prey abundance index (ra), predator-prey overlap (ov) as well as a interaction specific factor $(C)$. (a) Contribution of $C$ (each striped bar represents 1 interaction); (b) contribution of ra; and (c) contribution of ov. Bars in (a) and dashed lines in (b) and (c) indicate 2 SEs. The span argument for the LOESS smoother (lo) was 0.5

thereby a function of both the composition of the prey field as well as changes in predator-prey overlap (Table 3). Both predictor variables showed a highly significant $(<0.01)$ impact on relative stomach contents and increased the explained model deviance to $65.6 \%$ in the final model. Relative stomach content values showed a linear decrease with decreasing relative prey abundance (ra) (Fig. 2). Below an ra of 0.1 the decreasing trend was accelerated before slowing down again at very low levels (ra < 0.04). The dependence on predator-prey overlap (ov) was characterized by a fast decrease in relative stomach contents when the overlap felt below the threshold of 0.1 (Fig. 2). Above this threshold, a plateau was reached and the influence of predator-prey overlap changes on
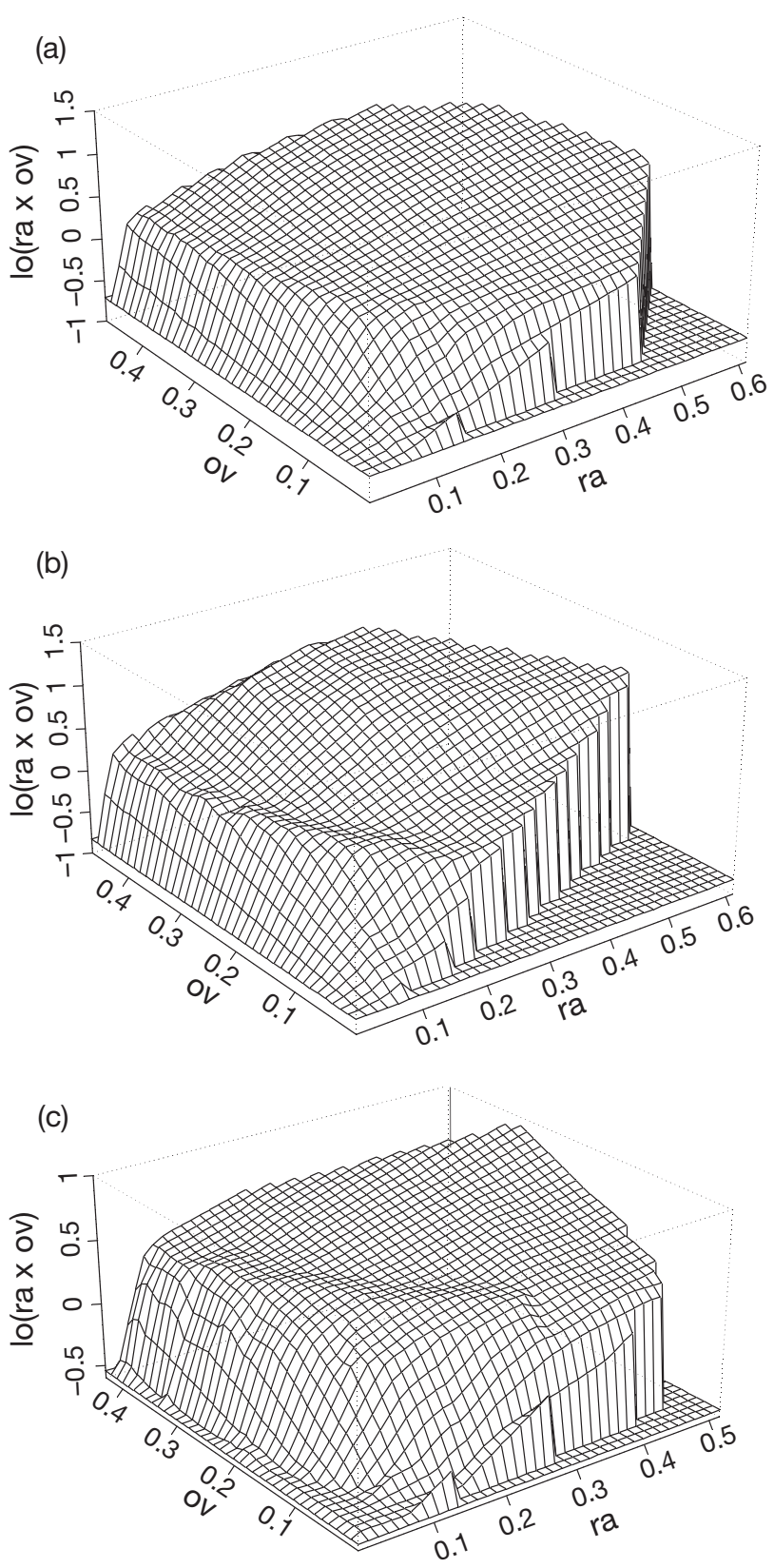

Fig. 3. Fitted relative stomach contents as a function of the interaction between relative prey abundance (ra) and predator-prey overlap (ov) as well as the predator-prey interaction specific factor ( $C$, not displayed). The relationships are shown for all analysed predator-prey interactions in (a), but also separately for cod as predator (b) and whiting as predator (c).

The span argument for the LOESS smoother (lo) was 0.5

the diet composition was only marginal. Relative prey abundance and predator-prey overlap alone without any corrections for catchability differences and predator preferences explained $25 \%$ of the model deviance.

Nearly the same model deviance $(65.0 \%)$ compared to the final model could be explained when modeling the influence of relative prey abundance and preda- 
Table 3. Analysis of deviance for variation in relative stomach contents with the relative prey abundance index (ra), the Schoener overlap index (ov) as well as a predator-prey interaction specific factor $(C)$. Res. df: residual df; Res. deviance: residual deviance left when including the variables given under 'Terms' in the GAM; Test: specifies the variables excluded or modelled as linear term in contrast to the global model

\begin{tabular}{|c|c|c|c|c|c|c|c|c|}
\hline Terms & Res. df & Res. deviance & Test & $\mathrm{df}$ & Deviance & $F$ & $\mathrm{p}$-value & $\mathrm{R}^{2}$ \\
\hline Null model & 391 & 40.46 & & & & & & \\
\hline \multicolumn{9}{|l|}{ Reference model } \\
\hline$C$ & 291 & 18.14 & & & & & & 55.2 \\
\hline \multicolumn{9}{|l|}{ Global model } \\
\hline$C+\mathrm{lo}(\mathrm{ra})+\mathrm{lo}(\mathrm{ov})$ & 283.02 & 13.93 & & & & & & 65.6 \\
\hline \multicolumn{9}{|l|}{ Simplifications } \\
\hline$C+l o(r a)$ & 286.78 & 15.28 & $-\operatorname{lo}(\mathrm{ov})$ & -3.76 & -1.36 & 7.39 & $<0.01$ & 62.2 \\
\hline$C+\mathrm{lo}$ (ov) & 287.22 & 17.11 & -lo(ra) & -4.20 & -3.19 & 15.55 & $<0.01$ & 57.7 \\
\hline$C+\mathrm{ra}+\mathrm{lo}(\mathrm{ov})$ & 286.24 & 14.40 & ra & -3.23 & -0.47 & 3.01 & $<0.05$ & 64.4 \\
\hline$C+\mathrm{lo}(\mathrm{ra})+\mathrm{ov}$ & 285.78 & 14.81 & ov & -2.76 & -0.88 & 6.56 & $<0.01$ & 63.4 \\
\hline lo(ra)+lo(ov) & 383.00 & 30.34 & $-C$ & -99.98 & -16.42 & 3.37 & $<0.01$ & 25.0 \\
\hline \multicolumn{9}{|l|}{ Final model } \\
\hline$C+\mathrm{lo}(\mathrm{ra})+\mathrm{lo}(\mathrm{ov})$ & 283.02 & 13.93 & & & & & & 65.6 \\
\hline \multicolumn{9}{|l|}{ Interaction model } \\
\hline$C+\mathrm{lo}(\mathrm{ra} \times \mathrm{ov})$ & 286.32 & 14.18 & & & & & & 65.0 \\
\hline$C$ & 291 & 18.14 & $-\mathrm{lo}\left(\mathrm{ra}^{*} \mathrm{ov}\right)$ & -4.68 & -3.96 & 17.18 & $<0.01$ & 55.2 \\
\hline \multicolumn{9}{|c|}{ Interaction model for cod only } \\
\hline Null model & 205 & 16.88 & & & & & & \\
\hline$C+$ lo(ra $\times$ ov $)$ & 148.3 & 6.56 & & & & & & \\
\hline$C$ & 153 & 9.25 & $-\mathrm{lo}\left(\mathrm{ra}{ }^{*} \mathrm{ov}\right)$ & -4.68 & -2.68 & 12.7 & $<0.01$ & \\
\hline \multicolumn{9}{|c|}{ Interaction model for whiting only } \\
\hline Null model & 185 & 23.46 & & & & & & \\
\hline$C+\operatorname{lo}(\mathrm{ra} \times \mathrm{ov})$ & 133.2 & 7.28 & & & & & & \\
\hline$C$ & 138 & 8.89 & $-\mathrm{lo}\left(\mathrm{ra}^{*} \mathrm{ov}\right)$ & -4.84 & -1.61 & 6.36 & $<0.01$ & \\
\hline
\end{tabular}

tor-prey overlap in one interaction term ( $\mathrm{ra} \times \mathrm{ov})$. In this model approach, the shape of the relationships at different combinations of relative prey abundances and predator-prey overlap values became obvious (Fig. 3). At small relative prey abundances $(<0.1)$ in combination with small predator-prey overlap values $(<0.1)$ particularly low relative stomach contents were observed. A fast increase in relative stomach contents occurred when relative prey abundance increased above 0.1 in combination with a predator-prey overlap below 0.1. Relative stomach contents also increased quickly at low relative prey abundances and a predator-prey overlap exceeding the threshold of 0.1. After the rapid increase, a plateau was reached with only moderate increasing relative stomach contents with increasing relative prey abundances and overlap values. The highest values for relative stomach contents were estimated at the combination of high relative abundance and high predator-prey overlap.

To test the universality of the relationships, the GAM with relative prey abundance and predator-prey overlap modelled in one interaction term was also fitted for the cod and whiting predator populations separately. The interaction term was also highly significant in these GAMs (Table 3). Both predator species re- sponded to changes in the prey field in a common way and the relationships showed equal shapes to the model with both predator species analysed together (Fig. 3). The fast decrease in relative stomach contents at low prey abundances combined with low spatial predator-prey overlap was characteristic for all GAMs.

\section{Predator-prey overlap}

The interannual variability in predator-prey overlap between larger and small cod $(10-15 \mathrm{~cm})$ was significantly influenced by the prey abundance index of cod (AP), the abundance index of the predator (APR) and the North Atlantic Oscillation index (NAO) (Table 4). The final model including the 3 significant terms could explain $61 \%$ of the interannual variability in predator - prey overlap in the 1st quarter. The reference model, which considered only differences in the spatial distribution of the different predator length classes, could not explain any of the overlap variabilities $\left(\mathrm{R}^{2}=0\right)$ (Table 4), although the overlap values tended to be lower for cod between 30 and $40 \mathrm{~cm}$ than for cod between 30 and $35 \mathrm{~cm}$. The relationship between prey 
abundance index and overlap was non-linear as well as the relationship with NAO. The overlap dropped down when AP became low (<1000) (Fig. 4). At a prey abundance index value of 1000, a maximum in the positive effect on predator-prey overlap was reached. Beyond the value of 1000, the positive effect of AP on overlap reached a constant value. Between NAO and overlap a strong decrease with increasing NAO values could be observed until a NAO value around 0.7 . At higher NAO values, the overlap was more or less stable at low levels. The relationship between overlap and APR was linear. This impression was confirmed by a non-significant $(>0.05)$ increase in model deviance when the degrees of freedom used were reduced by assuming a linear relationship instead of a non-linear smooth function. The higher the APR, the lower the overlap between large and small cod.

The interannual variability in predator-prey overlap between cod and clupeids was only significantly influenced by AP and NAO (Table 5). Over a wide range of prey abundances no clear effect on predator-prey overlap was observed (Fig. 5); only below an AP of 400000 did the overlap decrease with decreasing prey abundances. The overlap between cod and clupeids

Table 4. Analysis of deviance for variation in predator-prey overlap between large and small cod with the prey abundance index (AP), the predator abundance index (APR), the North Atlantic oscillation index (NAO) as well as a predator length specific constant $(C)$

\begin{tabular}{|c|c|c|c|c|c|c|c|c|}
\hline Terms & Res. df & Res. deviance & Test & df & Deviance & $F$ & $\mathrm{p}$-value & $\mathrm{R}^{2}$ \\
\hline Null model & 41 & 0.85 & & & & & & \\
\hline \multicolumn{9}{|l|}{ Reference model } \\
\hline$C$ & 40 & 0.85 & & & & & & 0.00 \\
\hline \multicolumn{9}{|l|}{ Global model } \\
\hline C+lo(AP)+lo(NAO)+lo(APR) & 24.89 & 0.24 & & & & & & 0.72 \\
\hline \multicolumn{9}{|l|}{ Simplifications } \\
\hline C+lo(AP)+lo(NAO) & 29.81 & 0.51 & $-\operatorname{lo}(\mathrm{APR})$ & -4.92 & -0.27 & 5.66 & $<0.01$ & 0.40 \\
\hline$C+\mathrm{lo}(\mathrm{AP})+\mathrm{lo}(\mathrm{APR})$ & 29.67 & 0.45 & $-\mathrm{lo}(\mathrm{NAO})$ & -4.78 & -0.21 & 4.58 & $<0.01$ & 0.47 \\
\hline$C+\operatorname{lo}(\mathrm{NAO})+\mathrm{lo}(\mathrm{APR})$ & 30.35 & 0.69 & $-\operatorname{lo}(\mathrm{AP})$ & -5.45 & -0.46 & 8.58 & $<0.01$ & 0.18 \\
\hline $\mathrm{C}+\mathrm{lo}(\mathrm{AP})+\mathrm{lo}(\mathrm{NAO})+\mathrm{APR}$ & 28.80 & 0.33 & APR & -3.91 & -0.09 & 2.40 & $>0.05$ & 0.61 \\
\hline $\mathrm{C}+\mathrm{lo}(\mathrm{AP})+\mathrm{NAO}+\mathrm{lo}(\mathrm{APR})$ & 28.68 & 0.37 & NAO & -3.79 & -0.13 & 3.60 & $<0.05$ & 0.57 \\
\hline$C+\mathrm{AP}+\mathrm{lo}(\mathrm{NAO})+\mathrm{lo}(\mathrm{APR})$ & 29.34 & 0.69 & $\mathrm{AP}$ & -4.45 & -0.45 & 10.29 & $<0.01$ & 0.19 \\
\hline \multicolumn{9}{|l|}{ Final model } \\
\hline$C+\mathrm{lo}(\mathrm{AP})+\mathrm{lo}(\mathrm{NAO})+\mathrm{APR}$ & 28.80 & 0.33 & & & & & & 0.61 \\
\hline
\end{tabular}

Table 5. Analysis of deviance for variation in predator-prey overlap between large cod and small clupeids with the prey abundance index (AP), the predator abundance index (APR), the North Atlantic oscillation index (NAO) as well as a predator length specific constant $(C)$

\begin{tabular}{|c|c|c|c|c|c|c|c|c|}
\hline Terms & Res. df & Res. deviance & Test & df & Deviance & $F$ & $\mathrm{p}$-value & $\mathrm{R}^{2}$ \\
\hline Null model & 41 & 1.00 & & & & & & \\
\hline \multicolumn{9}{|l|}{ Reference model } \\
\hline$C$ & 40 & 1.00 & & & & & & 0.00 \\
\hline \multicolumn{9}{|l|}{ Global model } \\
\hline$C+\mathrm{lo}(\mathrm{AP})+\mathrm{lo}(\mathrm{NAO})+\mathrm{lo}(\mathrm{APR})$ & 26.26 & 0.34 & & & & & & 0.66 \\
\hline \multicolumn{9}{|l|}{ Simplifications } \\
\hline$C+\mathrm{lo}(\mathrm{AP})+\mathrm{lo}(\mathrm{NAO})$ & 31.16 & 0.38 & $-\operatorname{lo}(\mathrm{APR})$ & -4.90 & -0.04 & 0.70 & $>0.05$ & 0.62 \\
\hline$C+\mathrm{lo}(\mathrm{AP})+\mathrm{lo}(\mathrm{APR})$ & 31.09 & 0.53 & -lo(NAO) & -4.83 & -0.19 & 3.06 & $<0.05$ & 0.47 \\
\hline$C+\mathrm{lo}(\mathrm{NAO})+\mathrm{lo}(\mathrm{APR})$ & 30.31 & 0.61 & $-\operatorname{lo}(\mathrm{AP})$ & -4.06 & -0.28 & 5.37 & $<0.01$ & 0.39 \\
\hline \multicolumn{9}{|l|}{ Intermediate result } \\
\hline$C+\operatorname{lo}(\mathrm{AP})+\mathrm{lo}(\mathrm{NAO})$ & 31.16 & 0.38 & & & & & & 0.62 \\
\hline$C+\operatorname{lo}(\mathrm{AP})$ & 35.98 & 0.61 & $-\operatorname{lo}(\mathrm{NAO})$ & -4.82 & -0.22 & 3.80 & $<0.01$ & 0.39 \\
\hline$C+\operatorname{lo}(\mathrm{NAO})$ & 35.24 & 0.67 & $-\operatorname{lo}(\mathrm{AP})$ & -4.08 & -0.29 & 5.76 & $<0.01$ & 0.33 \\
\hline$C+\mathrm{lo}(\mathrm{AP})+\mathrm{NAO}$ & 34.97 & 0.53 & NAO & -3.81 & -0.15 & 3.14 & $<0.05$ & 0.47 \\
\hline$C+\mathrm{lo}(\mathrm{NAO})+\mathrm{AP}$ & 34.24 & 0.63 & $\mathrm{AP}$ & -3.08 & -0.24 & 6.51 & $<0.01$ & 0.37 \\
\hline \multicolumn{9}{|l|}{ Final model } \\
\hline$C+\mathrm{lo}(\mathrm{AP})+\mathrm{lo}(\mathrm{NAO})$ & 31.16 & 0.38 & & & & & & 0.62 \\
\hline
\end{tabular}



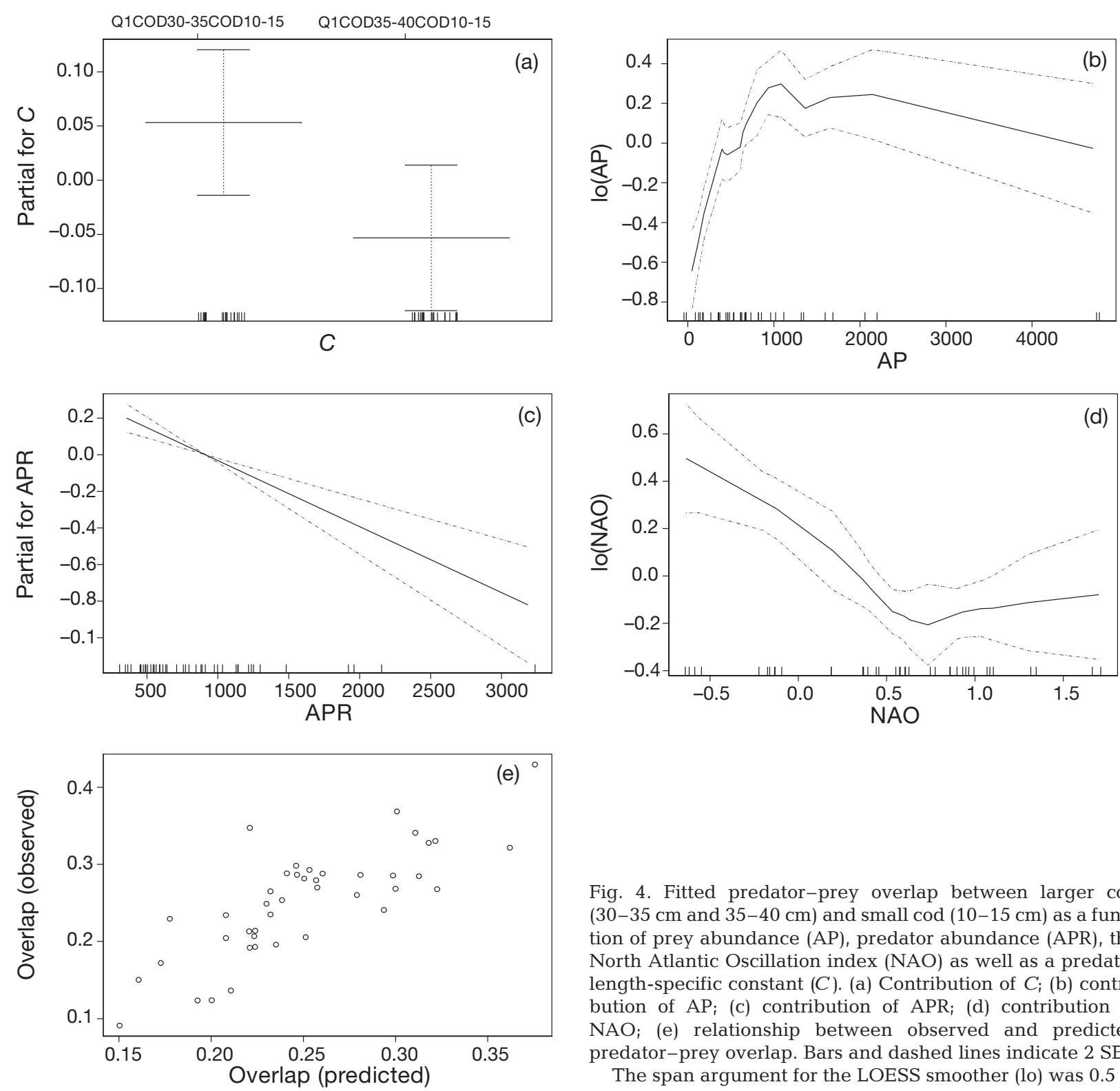

Fig. 4. Fitted predator-prey overlap between larger cod $(30-35 \mathrm{~cm}$ and $35-40 \mathrm{~cm})$ and small cod $(10-15 \mathrm{~cm})$ as a function of prey abundance (AP), predator abundance (APR), the North Atlantic Oscillation index (NAO) as well as a predator length-specific constant $(C)$. (a) Contribution of $C_{i}$ (b) contribution of $\mathrm{AP}_{i}$ (c) contribution of $\mathrm{APR}_{i}$ (d) contribution of $\mathrm{NAO}_{;}$(e) relationship between observed and predicted predator-prey overlap. Bars and dashed lines indicate 2 SEs.

The span argument for the LOESS smoother (lo) was 0.5

also decreased with increasing NAO values. This trend was only interrupted at NAO values around 0.5 where a local maximum could be found. The final model explained $62 \%$, the reference model $0 \%$, of the overlap index variability.

\section{DISCUSSION}

\section{Methods}

Two independent data sources (survey catch and stomach data) were used to detect relationships between relative stomach contents and the composi-

tion of the available prey field. This was done in a direct way and not influenced by any model assumptions in contrast to other studies carried out previously (e.g. analysis of the same stomach data inside the MSVPA model framework) (Larsen \& Gislason 1992). These advantages, however, made it necessary to draw subsamples from the original data to ensure equal coverage between the large-scale stomach and survey data. As a result, the total area of the subsamples differs from year to year. The number of ICES squares taken into account in the analysis varied between 27 and 114; therefore, our results may be influenced to some extent by an area effect. The additional area effect, however, does not matter for the 

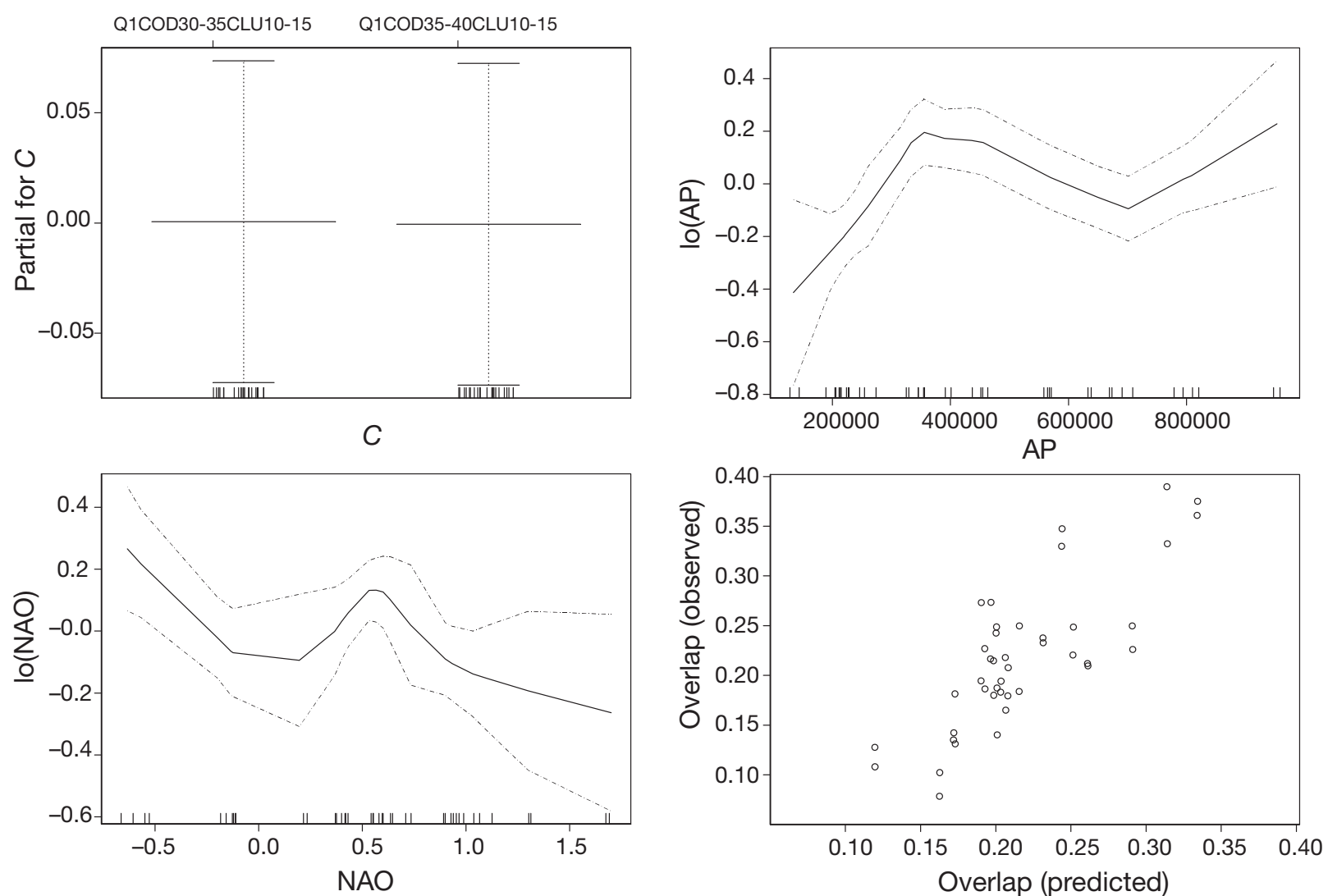

Fig. 5. Fitted predator-prey overlap between larger cod $(30-35 \mathrm{~cm}$ and $35-40 \mathrm{~cm})$ and small clupeids $(10-15 \mathrm{~cm})$ as a function of prey abundance (AP) and the North Atlantic Oscillation Index (NAO) as well as a predator length-specific constant (C). (a) Contribution of $C_{i}$ (b) contribution of $\mathrm{AP} ;$ (c) contribution of NAO; (d) relationship between predator-prey overlap observed and predicted from the final model. Bars and dashed lines indicate2 SEs. The span argument for the LOESS smoother (lo) was 0.5

purpose of this analysis. The relative stomach contents of the predator populations inside each subsample were contrasted only with the situation of the prey field in the respective subarea at the respective time. The variability in relative stomach contents between the different subsamples was only explained by the variability in the prey field. Whether these changes in the prey field are caused by changes in time or due to a different sampling area, however, does not affect the conclusions about the response of the predator populations within the covered areas towards the changes in the prey field.

As a second focus, processes determining the strength of predator-prey overlap were investigated. The overlap index was derived from survey data. The predator and prey abundance indices as predictive variables were derived from the same data source. This could theoretically lead to circular dependencies between overlap and abundance indices. Due to the formulation of the Schoener overlap index, however, this problem was avoided as much as possible. For the calculation of the overlap index, only information on the relative spatial distribution of the survey catches was used. The overlap index value was independent from absolute catch numbers. Information on absolute catch numbers, aggregated over the whole North Sea, was exclusively used for the predator and prey abundance index. Therefore, response and predictive variables were regarded as sufficiently independent.

\section{Response of cod and whiting populations to varying prey fields}

Changes in relative stomach contents between years were a function of both the composition of the prey field and spatial predator-prey overlap. The interplay between both variables led to a prey refuge when a prey becomes scarce and, additionally, the predatorprey overlap becomes low. The effect of the prey field composition alone also led to an accelerated decrease of relative stomach contents for relative prey abundances below 0.1 , which points towards positive prey switching. This effect on the diet composition, how- 
ever, was much weaker than the combined effect of both influences together. The emerging prey refuge at population level, however, must not be seen as a spatially separated hiding place. It has to be seen as a virtual refuge (May 1974) and any process leading to decreased predation mortalities for scarce prey can theoretically be responsible.

The observed prey refuge was created by changes in the diet composition of the predator populations alone since no changes in consumption rates were assumed. This assumption may be not valid especially for ecosystems with a lower number of alternative prey types (e.g. Baltic and Barents Seas). A reduction in consumption rates with decreasing prey availabilities would be a reasonable alternative assumption. This, however, would only further reduce the predation impact in the observed prey refuge, but do not reverse any of the conclusions of this analysis.

The existence of a combined effect between decreasing relative prey abundances and decreasing predator-prey overlap values on relative stomach contents could be also confirmed. The overlap dropped down when the prey abundance index became low, especially for small cod as prey. Therefore, the prey refuge created by low prey abundances and additional low overlap values seems to exist at least for cod. However, prey density-independent influences on predator-prey overlap (e.g. climate, predator population) could also control the strength of a prey refuge for a certain predator-prey interaction (see next section).

The existence of the prey refuge leads to a functional feeding response type III effect at low prey abundances (Holling 1959) on the population level only. Much of this Holling type III effect, however, was not caused by positive prey switching in its classical form, where an increase in predator preferences at increasing prey encounters are assumed at the individual level (Murdoch 1969). This would mean an active change in the diet selection behaviour of the predator. Instead, this effect was caused to a large extent by a passive change in the availability of the prey due to changes in predator-prey overlap. A reduction of the distribution area at low densities was reported for a number of prey populations (e.g. Marshall \& Frank 1994, Shepherd \& Lituak 2004). In our analysis the overlap between large and small cod dropped down at low prey abundances. Indeed, North Sea cod recruits between 10 and $15 \mathrm{~cm}$ condensed their distribution area in the 1st quarter towards the frontal areas at the outflow region of the Skagerak when becoming low in abundance (Fig. 6).

When a prey type increased its abundance or predator-prey overlap rose above 0.1 , the predator populations responded with a steep increase of the relative stomach contents for this prey type. After this rapid transition phase (relative prey abundance and overlap values between 0.1 and 0.2 ), the relative stomach contents increased only moderately with further increasing relative prey abundances and overlap values. A plateau was visible when modelling the influence of prey field composition and predator-prey overlap in 1 interaction term. The moderate increase of relative stomach contents already at relative prey abundances and overlap values around 0.2 is a hint towards an early saturation effect for abundant and well available prey types. This early saturation effect may has caused the observation of negative prey switching in former analyses (e.g. Larsen \& Gislason 1992, Rindorf et al. 1998) since it can lead to the observation of decreasing predator preferences for abundant prey. The effect itself could be explained by the presence of enough alternative food, since nearly no prey type could exceed a relative prey abundance of 0.5 in the modelled prey field.

Our observation of a Holling type III effect at low prey abundances stays in contrast to earlier findings which detected negative prey switching. However, our study not only looked at changes in the abundance of prey (e.g. Larsen \& Gislason 1992) but took changes in predator-prey overlap explicitly into account. We also carried out an analysis investigating the processes leading to the diet composition of predator populations at the large spatial scale and not at the local scale of single sampling stations (e.g. Rindorf et al. 1998, Rindorf \& Gislason 2005). For the first time, the discrepancies between the sampled North Sea stomach data showing so far negative prey switching behaviour and field observations of prey populations existing at low abundance levels could be resolved with our modelling approach.

\section{What determines spatial predator-prey overlap?}

Despite the already discussed density dependence on prey abundance, predator-prey overlap may vary due to environmental and climatic factors (e.g. Corten 1990, Murawski 1993, Beare et al. 2004). Increasing NAO values had a decreasing effect on the predatorprey overlap between larger and small cod as well as clupeids. Analysis of survey data showed that this is a result of a northward shift in the spatial distribution of larger cod during mild winters, which are associated with high NAO values (Rindorf \& Lewy 2006). Since small cod and especially sprat with its strong increasing abundances during the 1990s were distributed more in the southern and central part of the North Sea (visual interpretation from ICES maps for cod and sprat 10-15 cm; www.ices.dk/marineworld/ices-fishmap.asp) the overlap must decrease. 

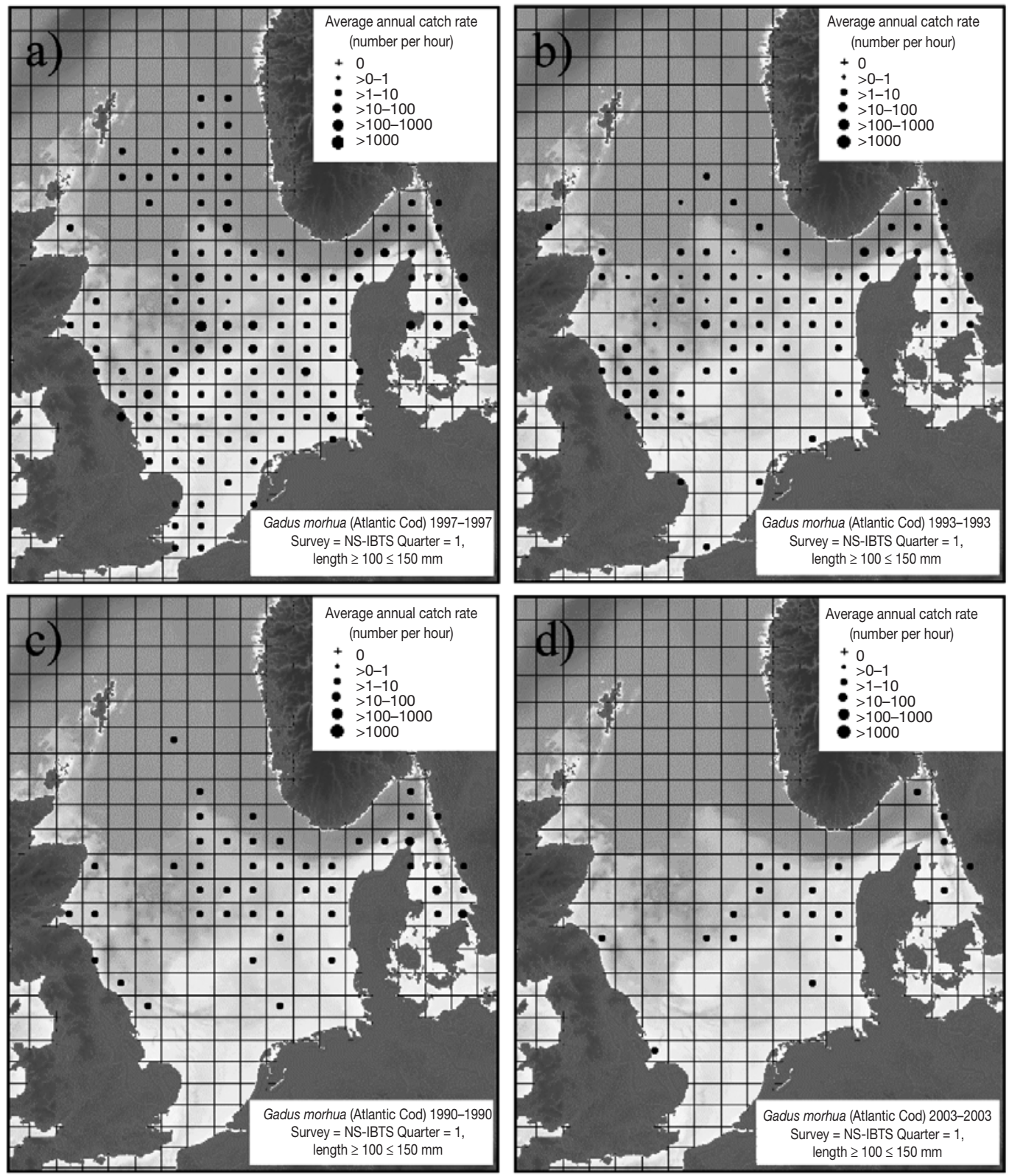

Fig. 6. Distribution of $10-15 \mathrm{~cm}$ cod catches in the IBTS quarter 1 survey. The distributions are shown for (a) 1997 and an abundance index of 4097; (b) 1993 and an abundance index of 804; (c) 1990 and an abundance index of 397 ; and (d) 2003 and an abundance index of 46. Maps were created with ICES fishmap (www.ices.dk/marineworld/ices-fishmap.asp)

The downward trend of predator-prey overlap between large and small cod with an increasing APR cannot be explained easily. The possibility of a spurious correlation is low since there was no significant correlation of APR with any of the other predictive variables. Whether there is a correlation with variables not taken into account in the GAM (e.g. temperature), however, cannot be ruled out. The negative effect of high predator abundances could be the result of cannibalism in areas of high predator abundance during the 2nd, 3rd and 4 th quarters of the previous year. Although the prey abundance index values were similar (around 650 ), the total area of distribution for small cod in the 1st quarter was much smaller in the year 1998 (found in 29 ICES squares) than in the years 2000 and 2002 (found in 68 or 44 ICES squares respectively). The predator abundance index values in 1998 were nearly twice as high as in the years 2000 and 2002. The potential of aggregating gadoids to locally deplete 0 -groups was demonstrated by Temming et al. (2007) for whiting. Preliminary results also suggest a negative correlation of high overlap values between large and small 
cod in the third quarter and the IBTS cod age 1 index in the 1st quarter of the following year (A. Kempf et al. unpubl. data). A reduced area of prey distribution during the 1st quarter, however, could be also the consequence of a predator avoidance strategy (e.g. Hardiman et al. 2004).

\section{Implications for prey population dynamics}

The presence of a Holling type III effect prevents prey populations from dying out. The decline in predator-prey overlap when prey populations become scarce is an important mechanism of this stabilizing effect. Although such a decline could be observed for all predator-prey interactions analysed, there may be other cases where such a decline in overlap is missing. The predator-prey overlap could also theoretically increase if a prey concentrates in areas where the predator has high abundances. Climate-induced distribution changes could also potentially overrule a prey density-dependent decrease in predator-prey overlap. Further analyses on processes determining predator-prey overlap for various predator-prey interactions are needed to fully determine whether all North Sea fish predator-prey interactions are generally stabilized due to a spatial overlap-induced prey refuge.

The steep increase of relative stomach contents straight after the observed prey refuge is in line with the predator pit theory (Holling 1965, Gascoigne \& Lipcus 2004). Growing prey populations first have to outgrow the abundance range with rapid increasing predation mortalities before they are able to expand their stock size towards high abundance values. Such predator pits are discussed as factors which prevent depleted fish stocks from recovery (e.g. northern cod, Shelton \& Healey 1999; fish larvae in general, Bakun 2006). Once a prey population is able to overcome the predator pit, the slower increase in relative stomach contents with further increases in prey abundance (and overlap) leads to reduced predation mortalities (number eaten/number in the field). This supports the expansion of the prey population towards the carrying capacity of the ecosystem. The analysed changes in the diet composition of cod and whiting populations suggest stable prey populations either at very low or at high prey abundance values. Between both conditions the stability is low because of rapid changes in predation impact.

The results of this study make clear that multi-species models parameterised with a Holling type II functional feeding response and assuming constant spatial predator-prey overlap in time do not realistically model important predator-prey dynamics especially when prey populations become scarce. Diet selection models parameterised with Holling type III-like functional feeding responses are more realistic. In addition, improved versions of diet selection submodels have to be developed that take the effect of changes in predator-prey overlap explicitly into account.

Acknowledgements. The authors thank the numerous colleagues on board the RVs and in the labs who produced the vast amount of stomach and survey data on which this study is based. Without these colleagues analyses would not have been possible.

\section{LITERATURE CITED}

Anonymous (1988) Report of the meeting of the coordinators of the stomach sampling project 1985-1987. ICES CM 1988/G:27

Bakun A (2006) Wasp-waist populations and marine ecosystem dynamics: navigating the 'predator pit' topographies. Prog Oceanogr 68:271-288

Baranova T (1992) On the growth of eastern Baltic cod. ICES CM 1992/J:29

Barnston G, Livezey RE (1987) Classification, seasonality and low-frequency atmospheric circulation patterns. Mon Weather Rev 115:1083-1126

Bax NJ (1991) A comparison of the fish biomass flow to fish, fisheries, and mammals on six marine ecosystems. ICES Mar Sci Symp 193:217-224

> Beare D, Burns F, Greig A, Jones G and others (2004) Longterm increases in prevalence of North Sea fishes having southern biogeographic affinities. Mar Ecol Prog Ser 284: 269-278

- Chesson J (1983) The estimation and analysis of preference and its relationship to foraging models. Ecology 64: $1297-1304$

Corten A (1990) Long-term trends in pelagic fish stocks of the North Sea and adjacent waters and their possible connection to hydrographic changes. Neth J Sea Res 25:227-235

Cushing DH (1982) Climate and fisheries. Academic Press, London

Daan N (1989) Database report of the stomach sampling project 1981. ICES Coop Res Rep No. 164

Dunne J, Brose U, Williams RJ, Martinez N (2005) Modeling food-web dynamics: complexity-stability implications. In: Belgrano A, Scharler UM, Dunne J, Ulanowicz RE (eds) Aquatic food webs: an ecosystem approach. Oxford University Press, Oxford, p 117-129

Gascoigne JC, Lipcus RN (2004) Allee effects driven by predation. J Appl Ecol 41:801-810

Gentleman W, Leising A, Frost B, Strom S, Murray J (2003) Functional responses for zooplankton feeding on multiple resources: a review of assumptions and biological dynamics. Deep-Sea Res II 50:2847-2875

> Hardiman JM, Johnson BM, Patrick JM (2004) Do predators influence the distribution of age-0 kokanee in a Colorado reservoir? Trans Am Fish Soc 133:1366-1378

Hasti TJ, Tibshirani RJ (1990) Generalized additive models. In: Cox DR, Hinkley DV, Reid N, Rubin DB, Silverman BW (eds) Monographs on statistics and applied probability, Vol 43. Chapman \& Hall, London

Helgason T, Gislason H (1979) VPA-analysis with species interaction due to predation. ICES CM 1979/G:52

Hislop J, Bromley PJ, Daan N, Gislason H and others (1997) Database report of the stomach sampling project 1991. 
ICES Coop Res Rep No. 219

Holling CS (1959) The components of predation as revealed by a study of small-mammal predation of the European pine sawfly. Can Entomol 91:293-320

Holling CS (1965) The functional response of predators to prey density and its role in mimicry and population regulation. Mem Entomol Soc Can 45:3-60

ICES (1991) Report of the multispecies assessment working group. ICES CM 1991/Assess:7

ICES (1992) Report of the multispecies assessment working group. ICES CM 1992/Assess:16

ICES (2003) Report of the study group on multispecies assessments in the North Sea. ICES CM 2003/D:09

ICES (2004) Report of the herring assessment working group for the area south of $62^{\circ} \mathrm{N}$ (HAWG). ICES CM 2004/ ACFM:18

ICES (2005) Report on the assessment of demersal stocks in the North Sea and Skagerrak ICES CM 2005/ACFM:07

Kempf A, Floeter J, Temming A (2006) Decadal changes in the North Sea food web between 1981 and 1991: implications for fish stock assessment. Can J Fish Aquat Sci 63: 2586-2602

Koester FW, Moellmann C (2000) Trophodynamic control by clupeid predators on recruitment success in Baltic cod? ICES J Mar Sci 57:310-323

Larsen JR, Gislason H (1992) MSVPA and prey/predator switching. ICES CM 1992/G:42

Magnusson KG (1995) An overview of the multispecies VPA: theory and applications. Rev Fish Biol Fish 5:195-212

Marshall CT, Frank KT (1994) Geographic responses of groundfish to variation in abundance: methods of detection and their interpretation. Can J Fish Aquat Sci 54:1504-1512

Marshall CT, Needle CL, Yaragina NA, Ajiad A, Gusev E (2004) Deriving condition indices from standard fisheries databases and evaluating their sensitivity to variation in stored energy reserves. Can J Fish Aquat Sci 61: 1900-1917

May RM 1974. Stability and complexity in model ecosystems. Princeton University Press, Princeton, NJ

Mueter FJ, Ladd C, Palmer MC, Norcross BL (2006) Bottomup and top-down controls of walleye pollock (Theragra chalcogramma) on the Eastern Bering Sea shelf. Prog Oceanogr 68:152-183

Editorial responsibility: Jake Rice, Ottawa, Canada
Murawski SA (1993) Climate change and marine fish distributions: forecasting from historical analogy. Trans Am Fish Soc 122:647-658

> Murdoch WW (1969) Switching in general predators: experiments on predator specificity and stability of prey populations. Ecol Monogr 39:335-354

Murdoch WW, Oaten A (1975). Predation and population stability. In: Macfadyen A (ed) Advances in ecological research 9. Academic Press, London, p 2-132

Pope JG 1979. A modified cohort analysis in which constant natural mortality is replaced by estimates of predation levels. ICES CM 1979/H:16, 8 p

Rindorf A, Gislason H (2005) Functional and aggregative response of North Sea whiting. J Exp Mar Biol Ecol 324: $1-19$

> Rindorf A, Lewy P (2006) Warm, windy winters drive cod north and homing of spawners keeps them there. J Appl Ecol 43:445-453

Rindorf A, Gislason H, Lewy P 1998. Does the diet of cod and whiting reflect the species composition estimated from trawl surveys? ICES CM CC:5

Schoener TW (1970) Nonsynchronous spatial overlap of lizards in patchy habitats. Ecology 51:408-418

Shelton PA, Healey BP (1999) Should depensation be dismissed as a possible explanation for the lack of recovery of the northern cod (Gadus morhua) stock? Can J Fish Aquat Sci 56:1521-1524

Shepherd TD, Lituak MK (2004) Density-dependent habitat selection and the ideal free distribution in marine fish spatial dynamics: considerations and cautions. Fish Fish 5: $141-152$

Sissenwine MP (1984) Why do fish populations vary? In: May RM (ed) Exploitation of marine communities. SpringerVerlag, New York, p 59-95

Temming A, Floeter J, Ehrich S (2007) Predation hot spots: large scale impact of local aggregations. Ecosystems 10: 865-876

Tsou TS, Collie JS (2001) Predation-mediated recruitment in the Georges Bank fish community. ICES J Mar Sci 58: 994-1001

$>$ Wu J, Loucks OL (1995) From balance of nature to hierarchical patch dynamics: a paradigm shift in ecology. Q Rev Biol 70:439-466

Submitted: November 7, 2007; Accepted: April 27, 2008

Proofs received from author(s): August 25, 2008 